Article

\title{
Synthesis of New Bis(3-hydroxy-4-pyridinone) Ligands as Chelating Agents for Uranyl Complexation
}

\author{
Bo Jin *, Rongzong Zheng, Rufang Peng * and Shijin Chu
}

State Key Laboratory Cultivation Base for Nonmetal Composites and Functional Materials, Southwest University of Science and Technology, Mianyang 621010, China; 6070831@sina.com (R.Z.);

chushijin@swust.edu.cn (S.C.)

* Correspondence: jinbo0428@163.com (B.J.); rfpeng2006@163.com (R.P.); Tel.: +86-816-241-9011 (B.J. \& R.P.)

Academic Editor: Wim Dehaen

Received: 22 January 2016 ; Accepted: 23 February 2016 ; Published: 8 March 2016

\begin{abstract}
Five new bis(3-hydroxy-4-pyridinone) tetradentate chelators were synthesized in this study. The structures of these tetradentate chelators were characterized by ${ }^{1} \mathrm{H}-\mathrm{NMR},{ }^{13} \mathrm{C}-\mathrm{NMR}, \mathrm{FT}-\mathrm{IR}$, UV-vis, and mass spectral analyses. The binding abilities of these tetradentate chelators for uranyl ion at $\mathrm{pH} 7.4$ were also determined by UV spectrophotometry in aqueous media. Results showed that the efficiencies of these chelating agents are dependent on the linker length. Ligand $4 b$ is the best chelator and suitable for further studies.
\end{abstract}

Keywords: chelating agent; 3-hydroxy-4-pyridinone; uranium; tetradentate chelator

\section{Introduction}

Uranium is introduced into the body by ingestion, inhalation, or through wounds. The risk of uranium contamination has considerably magnified because of the extensive use of uranium as nuclear fuel in fission reactors and as weapon-grade nuclear material. The hexavalent uranyl ion $\left[\mathrm{UO}_{2}{ }^{2+}\right.$, $\mathrm{U}(\mathrm{VI})$ ] is the most stable form in vivo [1] and is complexed in the blood by chelating agents, such as proteins or carbonates. Meanwhile, tissues, especially the kidney and bones, accumulate uranium for months to years, which will induce cancer and chemical intoxication [2-4]. Thus, uranium should be eliminated from the body by administration of nontoxic chelating agents that can form stable complexes with the uranyl ion.

Among the different chelators, 3-Hydroxy-4-pyridinones (3,4-HOPO) have emerged as one of the hotspots in studies that focus on heavy metal chelators because of their special bidentate structure, highly selective chelating capacity, and significant physiological activities [5-12]. To date, three kinds of 3,4-HOPO derivatives are available, namely bidentate hydroxypyridinones $[5,6]$, tetradentate hydroxypyridinones [7-9], and hexadentate hydroxypyridinones [10,11]. The ideal design for chelators is to synthesize the hydroxypyridinones, which have excellent chelating efficacy and high selectivity of interaction, with special biological receptors in one molecular unity. The chelating capacity of bidentate hydroxypyridinones is usually inferior to that of hexadentate desferrioxamine [13,14]. Hexadentate hydroxypyridinones have a higher chelating ability than hexadentate desferrioxamine, but the poor absorption caused by their high molecular weight limits their application [15]. Thus, tetradentate hydroxypyridinones have been one of most extensively investigated compounds among heavy metal chelators [16]. Recent studies have reported that the tetradentate hydroxypyridinones exhibit better assays in vivo such as high chelating efficacy for Fe and $\mathrm{Ga}$ as well as excellent hydrophilic character [17-20]. However, few studies have examined the hydroxypyridinone chelating uranyl ions. In this paper, a series of new tetradentate hydroxypyridinone chelators is reported, and the binding affinities towards a uranyl cation $\left(\mathrm{UO}_{2}{ }^{2+}\right)$ were examined with UV spectrophotometry. 


\section{Results and Discussion}

\subsection{Synthesis}

The synthesis of tetradentate hydroxypyridinones $\mathbf{4 a - e}$ is shown in Scheme 1. Starting from the commercially available 3-hydroxy-2-methyl-4-pyrone (maltol), the hydroxyl was protected with benzyl bromide and proceeded in excellent yield (93\%) to produce 3-benzyloxy-2-methyl-4-pyrone 1. Then 3-Benzyloxy-2-methyl-4-pyrone 1 was directly condensed with diamines or ammonia alcohols to provide benzyloxy-pyridone derivatives $2 \mathbf{a}-\mathbf{e}$ in $75 \%-89 \%$ yields. This method was similar to that described by Santos [18] but with minor modifications. In this study, for benzyloxy-pyridone 2a, compared with the method of Santos, the molar ratio of amines with pyrone $\mathbf{1}$ was increased from $1: 1$ to $3: 1$, and the corresponding yield of 2 a evidently increased from $40 \%$ to $87 \%$. The structures of benzyloxy-pyridones $\mathbf{2 a - e}$ contained a reactive hydroxyl or amino group, which could easily react with malonyl dichloride to yield the corresponding condensed products $\mathbf{3 a}-\mathbf{e}$. The malonyl dichloride is extremely active, so the reaction should be conducted in an ice bath and anhydrous conditions. Removal of benzyl from the oxygen of 3a-e catalytic hydrogenation conditions (14.5 psi $\mathrm{H}_{2}, 10 \% \mathrm{Pd} / \mathrm{C}$ as catalyst) proceeded smoothly with good yield (71\%-90\%) to produce tetradentate hydroxypyridinones $\mathbf{4 a - e}$.
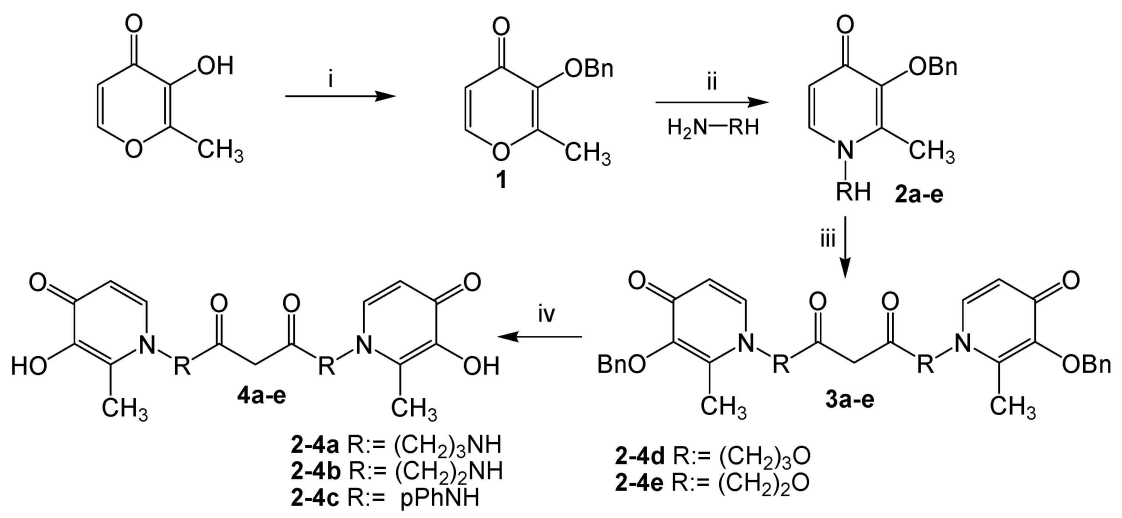

Scheme 1. Synthesis for the ligands 4a-e. Reagents and conditions: (i) $\mathrm{BnBr}, \mathrm{CH}_{3} \mathrm{OH}, 75^{\circ} \mathrm{C}$, reflux 6 h; (ii) $\mathrm{EtOH} / \mathrm{H}_{2} \mathrm{O}, \mathrm{NaOH}$, reflux $3 \mathrm{~h}, 10 \mathrm{M} \mathrm{HCl}$, until $\mathrm{pH}=1,10 \mathrm{M} \mathrm{NaOH}, \mathrm{pH}=11$; (iii) $\mathrm{CH}_{2}(\mathrm{COCl})_{2}$, dried $\mathrm{CH}_{2} \mathrm{Cl}_{2},{ }^{\circ} \mathrm{C}, 8 \mathrm{~h}$; (iv) $\mathrm{H}_{2}, \mathrm{Pd} / \mathrm{C}, \mathrm{CH}_{3} \mathrm{OH}, 4 \mathrm{~h}$.

\subsection{Characterization}

All products were purified and characterized by FT-IR, NMR, UV-vis and MS, and all characterizations were in accordance with the structures of the products.

The ${ }^{1} \mathrm{H}-\mathrm{NMR}$ spectra of compounds $\mathbf{2}-\mathbf{4 a}$ are shown in Figure 1. Compared with 2a, the signal of $\mathrm{NHCH}_{2} \mathrm{CH}_{2}$ - in 3a shifted to the low chemical field (from 2.75 to 3.31) because of the electrophilic effect of the $-\mathrm{CONH}$, and the singlet of the $-\mathrm{COCH}_{2} \mathrm{CO}-$ in $3 \mathbf{a}$ appeared at $\delta=3.20$ ppm. Compound 4a was obtained after the hydroxyls of 3a were deprotected. The peaks at 7.34 ppm of the benzene ring and $5.07 \mathrm{ppm}$ of the methylene disappeared when the benzyl group was removed, and the signal of the $\mathrm{CH}_{3}$-Pys shifted from $2.16 \mathrm{ppm}$ to $2.42 \mathrm{ppm}$.

The ${ }^{1} \mathrm{H}-\mathrm{NMR}$ spectra of $\mathbf{2} \mathbf{b}-\mathbf{e}, \mathbf{3 b}-\mathbf{e}$, and $\mathbf{4 b}-\mathbf{e}$ have similar results. The ${ }^{1} \mathrm{H}-\mathrm{NMR}$ spectra of $\mathbf{4 b}$ and $4 \mathrm{c}$ exhibit two doublets at $7.6 \mathrm{ppm}-7.7 \mathrm{ppm}$ and $6.45 \mathrm{ppm}-6.55 \mathrm{ppm}$ with $J_{\mathrm{AB}}=7.5 \mathrm{~Hz}$ for the two nonequivalent protons in the pyridine ring. Compared with $4 \mathbf{d}$ and $4 \mathbf{e}$, the signals of the pyridine ring protons appeared in the higher field because the oxygen atom is more electronegative than the nitrogen atom. The signals of the two nonequivalent protons in the pyridine rings of $\mathbf{4 d}$ and $4 \mathbf{e}$ appeared at $8.30 \mathrm{ppm}-8.33 \mathrm{ppm}(\mathrm{d}, J=7.2 \mathrm{~Hz}, 1 \mathrm{H})$ and $7.23 \mathrm{ppm}-7.25 \mathrm{ppm}(\mathrm{d}, J=7.2 \mathrm{~Hz}, 1 \mathrm{H})$, respectively. Additionally, the signals of $-\mathrm{COCH}_{2} \mathrm{CO}-$ in $4 \mathbf{d}$ and $4 \mathbf{e}$ appeared in a lower field than in $4 \mathrm{~b}$ and $4 \mathrm{c}$ under the same condition. The singlet of $-\mathrm{COCH}_{2} \mathrm{CO}-$ in $4 \mathbf{b}$ and $4 \mathrm{c}$ appeared at $3.0 \mathrm{ppm}-3.1 \mathrm{ppm}$, whereas that of $\mathbf{4 d}$ and $4 \mathbf{e}$ appeared at 3.6 ppm-3.8 ppm, respectively. 


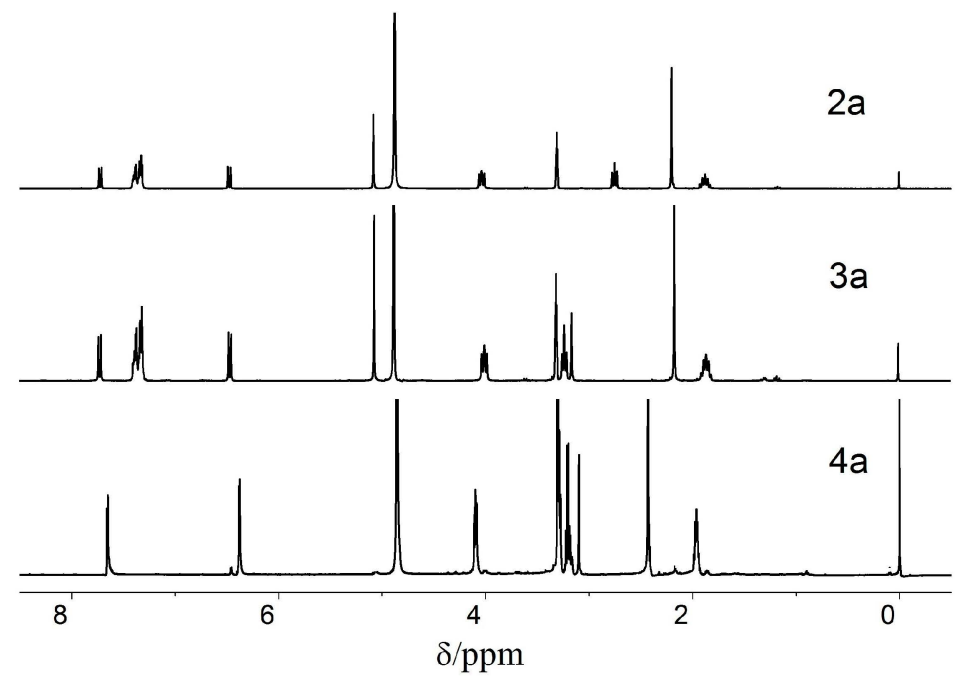

Figure 1. The ${ }^{1} \mathrm{H}-\mathrm{NMR}$ spectra of $\mathbf{2 a}\left(\mathrm{CD}_{3} \mathrm{OD}\right), \mathbf{3} \mathbf{a}\left(\mathrm{CD}_{3} \mathrm{OD}\right)$ and $\mathbf{4 a}\left(\mathrm{DMSO}-d_{6}\right)$.

\subsection{Complexation}

Although present metal-complexation studies are focused on a set of three-charged hard metal ions [21,22] (e.g., $\mathrm{Fe}, \mathrm{Al}$, and $\mathrm{Ga}$ ), the current study on decorporation [23] for $\mathrm{UO}_{2}{ }^{2+}$ is based on the extreme damage to the environment caused by uranyl cations $\left(\mathrm{UO}_{2}{ }^{2+}\right)$ in biological systems. In this paper, the complexation behavior of tetradentate hydroxypyridinones $4 \mathbf{a}-\mathbf{e}$ and the uranyl cation was evaluated by the spectrophotometric method [24,25].

We defined:

$\mathrm{M}=\mathrm{UO}_{2}{ }^{2+} ; \mathrm{L}=$ ligands $4 \mathbf{a}-\mathbf{e}$

$\mathrm{C}=[\mathrm{M}]+[\mathrm{L}] ; \mathrm{x}=[\mathrm{M}] / \mathrm{C}$

The coordination numbers $(\mathrm{M}: \mathrm{L})$ and the corresponding complex stability constants of the five tetradentate hydroxypyridinones $4 \mathbf{a}-\mathbf{e}$ toward $\mathrm{UO}_{2}{ }^{2+}$ at $\mathrm{pH} 7.4$ were measured with the method of equivalent molarity. The UV-vis spectra of the various metal-to-ligand molar ratios for the $\mathrm{UO}_{2}{ }^{2+}$-ligand 4a-e system at $\mathrm{pH} 7.4$ are shown in Figure 2. $\mathrm{UO}_{2}{ }^{2+}$ has an absorption peak at 229 $\mathrm{nm}$, the peak at $278 \mathrm{~nm}$ was a characteristic absorption of ligand $4 \mathbf{a}$, and a new peak at $303 \mathrm{~nm}$ appeared, which indicated that a new peak was the characteristic of the $\mathrm{UO}_{2}{ }^{2+}$-ligand 4 a complexation (Figure 2a). To construct the Job plot, the absorbance values were normalized according to the complex absorbance, and the experimental absorbance values of the $\mathrm{UO}_{2}{ }^{2+}$-ligand 4 a complexation at $\mathrm{pH} 7.4$ are plotted against the mole fraction (Figure 2b). The result shows that the complex stoichiometry for the complexation of $\mathrm{UO}_{2}{ }^{2+}$-ligand $4 \mathrm{a}$ at $\mathrm{pH} 7.4$ is $M / L=2: 3(\mathrm{x}=0.4)$. This value indicates that the three ligand molecules could bridge two bis-chelated $\mathrm{UO}_{2}{ }^{2+}$ centers under the effect of polar solvent molecules to complete their coordination sphere at $\mathrm{pH}$ 7.4.

Then ligands 4a-e complex with the uranyl, and the formation constants (log K) for the ligands could be calculated as follows:

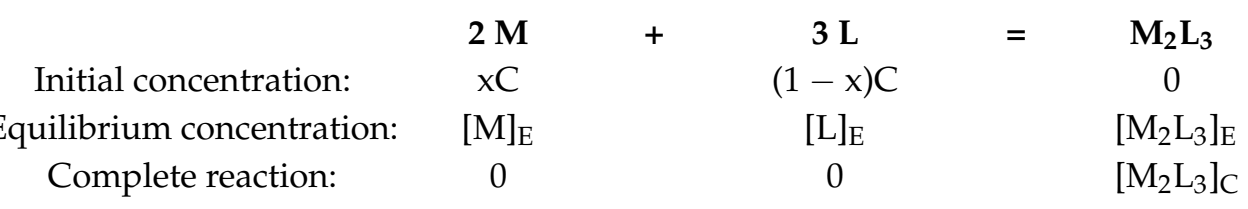

Based on the Lambert-Beer law:

$$
\frac{A_{E}}{\left[M_{2} L_{3}\right]_{E}}=\frac{A_{C}}{\left[M_{2} L_{3}\right]_{C}} \Rightarrow\left[M_{2} L_{3}\right]_{E}=\frac{A_{E}\left[M_{2} L_{3}\right]_{C}}{A_{C}}
$$




$$
\log K=\frac{\left[M_{2} L_{3}\right]_{E}}{[M]_{E}^{2}[L]_{E}^{3}}=\log \frac{\left[M_{2} L_{3}\right]_{E}}{\left\{x C-2\left[M_{2} L_{3}\right]_{E}\right\}^{2}\left\{(1-x) C-3\left[M_{2} L_{3}\right]_{E}\right\}^{3}}
$$

The complex stability constant of $4 \mathbf{a}$ and $\mathrm{UO}_{2}{ }^{2+}$ at $\mathrm{pH} 7.4$ was calculated by Equation (1), and the corresponding $\log \mathrm{K}_{\text {cond }} \mathrm{U}-\mathrm{L}$ 4a at $7.4 \mathrm{pH}$ levels was 21.7. The corresponding complex stability constants of other ligands were also calculated by Equation (1), and the results are shown in Table 1.

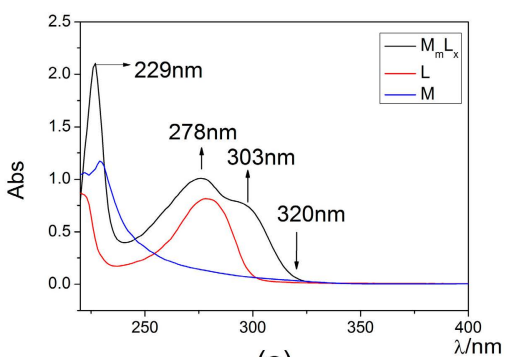

(a)

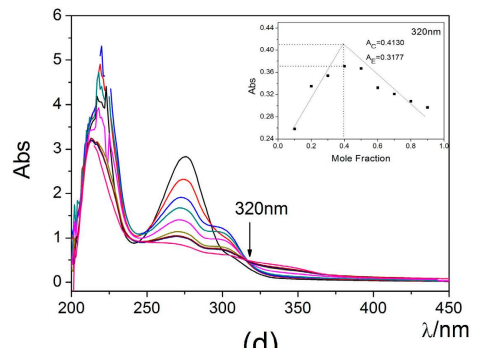

(d)

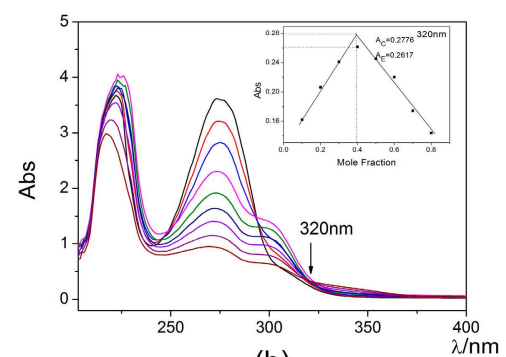

(b)

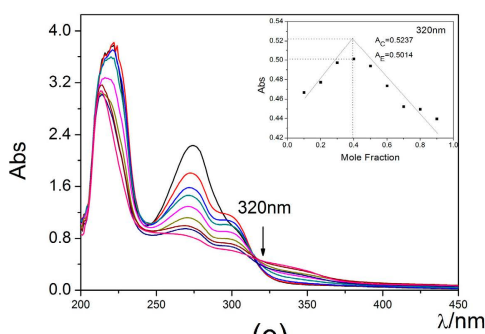

(e)

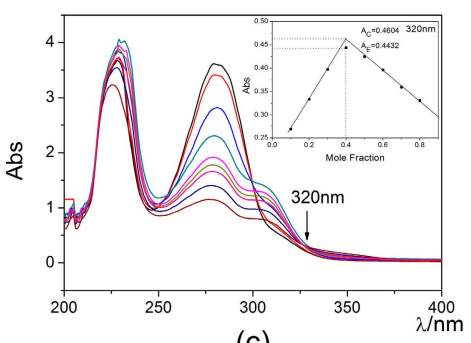

(c)

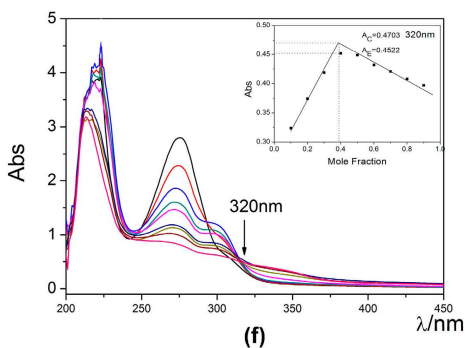

Figure 2. UV-vis absorption spectra of the various metal-to-ligand molar ratios for the $\mathrm{UO}_{2}{ }^{2+}$-Ligand 4a-e system at $\mathrm{pH}$ 7.4: $\mathrm{C}=4.00 \times 10^{-4} \mathrm{M}, \mathrm{T}=25^{\circ} \mathrm{C}, \mathrm{I}=0.1 \mathrm{M} \mathrm{KNO}_{3}$ : (a) The spectrophotometric absorption curves of the $\mathrm{UO}_{2}{ }^{2+}$, ligand $4 \mathbf{a}$ and $\mathrm{UO}_{2}{ }^{2+}$-ligand $4 \mathbf{a}$; (b) $\mathrm{UO}_{2}{ }^{2+}$-Ligand 4a system; (c) $\mathrm{UO}_{2}{ }^{2+}$-Ligand $\mathbf{4 b}$ system; (d) $\mathrm{UO}_{2}{ }^{2+}$-Ligand $4 \mathbf{c}$ system; (e) $\mathrm{UO}_{2}{ }^{2+}$-Ligand $4 \mathbf{d}$ system; (f) $\mathrm{UO}_{2}{ }^{2+}$-Ligand 4e system. All illustrations were obtained from the wavelength of $320 \mathrm{~nm}$.

Table 1. Summary of the $\log \mathrm{K}_{\mathrm{cond}}$ of ligand $-\mathrm{UO}_{2}{ }^{2+}(\mathrm{pH}=7.4 \pm 0.1)$.

\begin{tabular}{cc}
\hline $\mathrm{L}$ & $\log \mathrm{K}_{\text {cond }} \mathrm{U}-\mathrm{L} /(\mathrm{pH}=7.4)$ \\
\hline $\mathbf{4 a}$ & 21.7 \\
$4 \mathbf{b}$ & 22.7 \\
$4 \mathrm{c}$ & 18.6 \\
$4 \mathrm{~d}$ & 21.4 \\
$4 \mathrm{e}$ & 22.2 \\
\hline
\end{tabular}

Although the structures of Ligands $4 \mathbf{a}-\mathbf{e}$ are similar, some consistent differences are apparent. The change of the linker length has a great influence on the their U(VI) chelation efficiency [26-28]. As the length of the linker increases, the angle formed between the uranium and two phenolic oxygen donors also becomes greater, and it leads to an increase of the strain in this complex. [29] As a result of the strain imposed by the linker, that two carbon atoms may be considered the optimal length is consistent with the high efficacy of ligands $4 \mathbf{b}$ and $4 \mathbf{e}$ for in vivo uranyl chelation.

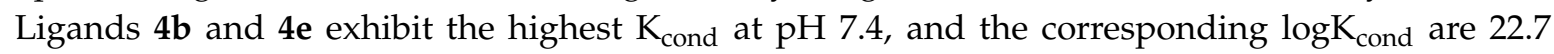
and 22.2. The modest reduction of body uranium in animals by the injection of bidentate Tiron (4,5-dihydroxy-1,3-benzenedisulfonic acid, disodium salt) and its U(VI)-catechol complex (log KML ) is 15.9 [29-31], which suggests the U(VI)-Ligands $\mathbf{4 b}$ complex and U(VI)-Ligands $4 \mathbf{e}$ complex Ligands $4 \mathrm{~b}$ and $4 \mathrm{e}$ exhibit higher stability than the U(VI)-Tiron complex. Thus, Ligands $4 \mathrm{~b}$ and $4 \mathbf{e}$ are most suitable for further studies. 


\section{Materials and Methods}

\subsection{General}

The organic reagents used were pure commercial products from Aladdin. The solvents were purchased from Chengdu Kelong Chemical Reagents Co. (Sichuan, China). Anhydrous $\mathrm{CH}_{2} \mathrm{Cl}_{2}$ was distilled prior to use. The 300-400 mesh silica gel was purchased from Qingdao Hailang. The ${ }^{1} \mathrm{H}-\mathrm{NMR},{ }^{13} \mathrm{C}-\mathrm{NMR}$ spectra were recorded on Bruker Avance 300, Avance 400, or Avance 600 spectrometer (Carlsruhe, Germany). The FTIR spectra were obtained from Nicolet 380 FTIR spectrophotometer (Thermo Fisher Nicolet, Madison, WI, USA) with a resolution of $4 \mathrm{~cm}^{-1}$ from $400 \mathrm{~cm}^{-1}$ to $4000 \mathrm{~cm}^{-1}$. UV-vis spectrophotometer (Thermo Scientific Evolution 201, Waltham, MA, USA) used had a double-beam light source from $190 \mathrm{~nm}$ to $1100 \mathrm{~nm}$. Mass spectral analysis was conducted using Varian 1200 LC/MS (Palo Alto, CA, USA).

\subsection{Synthesis}

Synthesis of 3-benzyloxy-2-methyl-4-pyrone (1). To a solution of $10.00 \mathrm{~g}$ 3-hydroxy-2-methyl-4-pyrone (79 mmol) containing the equivalent amount of $\mathrm{NaOH}(3.16 \mathrm{~g}, 79 \mathrm{mmol})$ in $100 \mathrm{~mL}$ methanol, $13 \mathrm{~mL}$ benzyl bromide $(90 \mathrm{mmol})$ was dropwise added and then stirred for $6 \mathrm{~h}$ under reflux temperature. After cooling, the reaction mixture was evaporated under vacuum, and the residual oil was resolved in $50 \mathrm{~mL}$ dichloromethane and washed with $5 \% \mathrm{NaOH}$ aqueous solution $(5 \times 30 \mathrm{~mL})$ and water $(3 \times 50 \mathrm{~mL})$. The organic solution was evaporated to dryness to obtain the pure product as pale oil $(15.7 \mathrm{~g}, 93 \%)$. UV-vis $\left(\mathrm{CH}_{3} \mathrm{OH}\right): \lambda_{\max }=219,260 \mathrm{~nm}$. FT-IR $(\mathrm{KBr}): v=3065,3031,2958,2877,1644,1575$, $1496,1455,1428,1253,1186,1079,973,915,832,751,703 \mathrm{~cm}^{-1} .{ }^{1} \mathrm{H} \mathrm{NMR}\left(300 \mathrm{MHz}, \mathrm{CDCl}_{3}\right): \delta=7.57(\mathrm{~d}$, $J=6.0 \mathrm{~Hz}, 1 \mathrm{H}), 7.25-7.40(\mathrm{~m}, 5 \mathrm{H}), 6.33(\mathrm{~d}, J=6.0 \mathrm{~Hz}, 1 \mathrm{H}), 5.13\left(\mathrm{~s}, 2 \mathrm{H}, \mathrm{CH}_{2} \mathrm{Ph}\right), 2.06\left(\mathrm{~s}, 3 \mathrm{H}, \mathrm{CH}_{3}\right) \mathrm{ppm}$. MS (APCI, $\left.\mathrm{CH}_{3} \mathrm{OH}\right) \mathrm{m} / z(\%)=217(100)[\mathrm{M}+\mathrm{H}]^{+} . \mathrm{C}_{13} \mathrm{H}_{12} \mathrm{O}_{3}$ (216.3): calcd. C 72.22, $\mathrm{H}$ 5.56; found: $\mathrm{C}$ $72.43, \mathrm{H} 5.47$.

Synthesis of (3'-aminopropyl)-3-benzyloxy-2-methyl-4-pyridinone (2a). First $3 \mathrm{~g}$ 3-Benzyoxy-2-methyl4-pyrone (13.9 mmol), $3.5 \mathrm{~mL} \mathrm{1,3-diaminopropane}(42.1 \mathrm{mmol})$ and $0.5 \mathrm{~g} \mathrm{NaOH}$ were added in a EtOH-water mixture $(20 / 15) \mathrm{mL}$, and then stirred at $75^{\circ} \mathrm{C}$ for $3 \mathrm{~h}$. After cooling, $2 \mathrm{M} \mathrm{HCl} \mathrm{was} \mathrm{added}$ until the $\mathrm{pH}=1$, and the reaction mixture was evaporated under vacuum. The residue was washed with acetone and dissolved in $20 \mathrm{~mL}$ water. Then the aqueous was basified with $10 \mathrm{M} \mathrm{NaOH}$ until $\mathrm{pH}=12$, and extracted with dichloromethane $(5 \times 30 \mathrm{~mL})$. The organic solution was evaporated to dryness to obtain the faint yellow oil $(3.5 \mathrm{~g}, 87 \%)$. UV-vis $\left(\mathrm{CH}_{3} \mathrm{OH}\right): \lambda_{\max }=213,277 \mathrm{~nm}$. FT-IR $(\mathrm{KBr}$ ): $v=3432(\mathrm{~N}-\mathrm{H}), 3063,3030(\mathrm{C}-\mathrm{H}, \mathrm{Ar}), 2492,2872(\mathrm{C}-\mathrm{H}), 1622(\mathrm{C}=\mathrm{O}), 1550,1250,838,752,703 \mathrm{~cm}^{-1}$. ${ }^{1} \mathrm{H}-\mathrm{NMR}\left(300 \mathrm{MHz}, \mathrm{CD}_{3} \mathrm{OD}\right): \delta=7.73(\mathrm{~d}, J=6.0 \mathrm{~Hz}, 1 \mathrm{H}), 7.30-7.42(\mathrm{~m}, 5 \mathrm{H}), 6.47(\mathrm{~d}, J=7.4 \mathrm{~Hz}, 1 \mathrm{H})$, $5.08\left(\mathrm{~s}, 2 \mathrm{H}, \mathrm{CH}_{2} \mathrm{Ph}\right), 4.03(\mathrm{t}, J=7.5 \mathrm{~Hz}, 2 \mathrm{H}), 2.75\left(\mathrm{t}, J=7.2 \mathrm{~Hz}, 2 \mathrm{H}, \mathrm{NH}_{2} \mathrm{CH}_{2} \mathrm{CH}_{2}\right), 2.19\left(\mathrm{~s}, 3 \mathrm{H}, \mathrm{CH}_{3}\right), 1.87$ $\left(\mathrm{m}, 2 \mathrm{H}, \mathrm{CH}_{2} \mathrm{CH}_{2} \mathrm{CH}_{2}\right)$ ppm. MS (APCI) $m / z(\%)=273.0(100)[\mathrm{M}+\mathrm{H}]^{+} . \mathrm{C}_{16} \mathrm{H}_{20} \mathrm{O}_{2} \mathrm{~N}_{2}$ (272.1): calcd. C 70.59, H 7.35, N 10.29; found: C 70.61, H 7.37, N 10.24.

Synthesis of $N, N^{\prime}$-bis(4-(3-benzyloxy-2-methyl-4-pyridinone)propyl)malonamide (3a). First $0.4 \mathrm{~g}$ (3'-aminopropyl)3-benzyloxy-2-methyl-4-pyridinone $(1.5 \mathrm{mmol})$ and $2 \mathrm{~mL}$ triethylamine were added in $50 \mathrm{~mL}$ dichloromethane, then mixture was stirred at $0{ }^{\circ} \mathrm{C}$ under $\mathrm{N}_{2}$. Then $75 \mu \mathrm{L}$ malonyl dichloride was diluted with $20 \mathrm{~mL}$ dichloromethane and then dropwise added slowly and consecutively keeping the temperature at $0{ }^{\circ} \mathrm{C}$ for $8 \mathrm{~h}$. The mixture was purified by chromatography on a silica-gel column with the methanol: chloroform $=1: 6$ as eluent, the pure product was white powder $(0.29 \mathrm{~g}, 64 \%)$. UV-vis $\left(\mathrm{CH}_{3} \mathrm{OH}\right): \lambda_{\max }=213,279 \mathrm{~nm}$. FT-IR $(\mathrm{KBr}): v=3226(\mathrm{~N}-\mathrm{H}), 3063(\mathrm{C}-\mathrm{H}, \mathrm{Ar}), 2935,2879,1654,1624$, $1559,1518,1249,1249,1218,1160,1036,975,833,750,703 \mathrm{~cm}^{-1} .{ }^{1} \mathrm{H}-\mathrm{NMR}\left(300 \mathrm{MHz}, \mathrm{CD}_{3} \mathrm{OD}\right): \delta=7.72$ $(\mathrm{d}, J=7.2 \mathrm{~Hz}, 2 \mathrm{H}), 7.29-7.41(\mathrm{~m}, 10 \mathrm{H}), 6.48(\mathrm{~d}, J=7.2 \mathrm{~Hz}, 2 \mathrm{H}), 5.07\left(\mathrm{~s}, 4 \mathrm{H}, \mathrm{CH}_{2} \mathrm{Ph}\right), 4.00(\mathrm{t}, J=7.5 \mathrm{~Hz}$, $\left.4 \mathrm{H}, \mathrm{NHCH}_{2} \mathrm{CH}_{2} \mathrm{CH}_{2}\right), 3.31\left(\mathrm{t}, \mathrm{J}=6.0 \mathrm{~Hz}, 4 \mathrm{H}, \mathrm{NHCH}_{2} \mathrm{CH}_{2} \mathrm{CH}_{2}\right), 3.20\left(\mathrm{~s}, 2 \mathrm{H}, \mathrm{COCH}{ }_{2} \mathrm{CO}\right), 2.16(\mathrm{~s}, 6 \mathrm{H}$, $\left.\mathrm{CH}_{3}\right), 1.87\left(\mathrm{~m}, 4 \mathrm{H}, \mathrm{CH}_{2} \mathrm{CH}_{2} \mathrm{CH}_{2}\right)$ ppm. MS (APCI) $m / z(\%)=613(100)[\mathrm{M}+\mathrm{H}]^{+} . \mathrm{C}_{35} \mathrm{H}_{40} \mathrm{O}_{6} \mathrm{~N}_{4}(612)$ : calcd. C 68.63, H 6.54, N 9.15; found: C 68.42, H 6.83, N 9.51. 
Synthesis of $N, N^{\prime}$-bis(4-(3-hydroxy-2-methyl-4-pyridinone)propyl)malonamide (4a). First $40 \mathrm{mg} 10 \% \mathrm{Pd} / \mathrm{C}$ was added in a solution of $N, N^{\prime}$-bis(4-(3-benzyloxy-2-methyl-4-pyridinone)propyl)malonamide ( $0.2 \mathrm{~g}$, $3.7 \mathrm{mmol})$ in methanol $(50 \mathrm{~mL})$, then the mixture was stirred under $\mathrm{H}_{2}(1 \mathrm{~atm})$ for $4 \mathrm{~h}$ at room temperature. After filtration, the solvent was evaporated under reduced pressure and the product was obtained as the white powder $(0.13 \mathrm{~g}, 89 \%)$. UV-vis $\left(\mathrm{CH}_{3} \mathrm{OH}\right): \lambda_{\max }=279 \mathrm{~nm}$. FT-IR $(\mathrm{KBr}): v=3069$, 2930, $1656\left(\mathrm{C}=\mathrm{OCH}_{2}\right), 1627(\mathrm{PyC}=\mathrm{O}), 1561,1509,1251\left(\mathrm{C}=\mathrm{ONH}_{2}\right), 1035,832 \mathrm{~cm}^{-1} \cdot{ }^{1} \mathrm{H}-\mathrm{NMR}(600 \mathrm{MHz}$, DMSO- $\left.d_{6}\right): \delta=7.64(\mathrm{~d}, J=7.2 \mathrm{~Hz}, 2 \mathrm{H}), 6.48(\mathrm{~d}, J=7.2 \mathrm{~Hz}, 2 \mathrm{H}), 4.10\left(\mathrm{t}, J=7.5 \mathrm{~Hz}, 4 \mathrm{H}, \mathrm{NHCH}_{2} \mathrm{CH}_{2} \mathrm{CH}_{2}\right)$, $3.31\left(\mathrm{t}, J=6.0 \mathrm{~Hz}, 4 \mathrm{H}, \mathrm{NHCH}_{2} \mathrm{CH}_{2} \mathrm{CH}_{2}\right), 3.21\left(\mathrm{~s}, 2 \mathrm{H}, \mathrm{COCH}_{2} \mathrm{CO}\right), 2.42\left(\mathrm{~s}, 6 \mathrm{H}, \mathrm{CH}_{3}\right), 1.96(\mathrm{~m}, 4 \mathrm{H}$, $\mathrm{CH}_{2} \mathrm{CH}_{2} \mathrm{CH}_{2}$ ) ppm. ${ }^{13} \mathrm{C}-\mathrm{NMR}\left(150 \mathrm{MHz}\right.$, DMSO- $\left.d_{6}\right): \delta=169.19,168.48,145.95,137.55,131.33,128.01$, $51.43,46.52,35.98,30.06,10.46$ ppm. MS (APCI) $m / z(\%)=217(100)[\mathrm{M}+2 \mathrm{H}]^{+} . \mathrm{C}_{21} \mathrm{H}_{28} \mathrm{O}_{6} \mathrm{~N}_{4}(432)$ : calcd. C 58.33, H 6.48, N 12.96; found: C 57.97, H 6.51, N 12.85.

Synthesis of (3'-aminoethyl)-3-benzyloxy-2-methyl-4-pyridinone (2b). First $3 \mathrm{~g}$ 3-benzyoxy-2-methyl-4-pyrone $(13.9 \mathrm{mmol})$ and $3.3 \mathrm{~mL}$ ethanediamine $(49.3 \mathrm{mmol})$ were added in a EtOH-water mixture $(20 / 15)$ $\mathrm{mL}$, then $0.5 \mathrm{~g} \mathrm{NaOH}$ was added and stirred at $70^{\circ} \mathrm{C}$ for $4 \mathrm{~h}$. After cooling, $2 \mathrm{M} \mathrm{HCl}$ was added until the $\mathrm{pH}=1$ and the solvent was evaporated. The residue was washed with acetone and dissolved in $20 \mathrm{~mL}$ water. The obtained solution was basified with $10 \mathrm{M} \mathrm{NaOH}$ until $\mathrm{pH} \approx 12$ and extracted with dichloromethane $(5 \times 30 \mathrm{~mL})$. The organic phase was evaporated and obtained the flavescent oil $(2.84 \mathrm{~g}, 74 \%)$. UV-vis $\left(\mathrm{CH}_{3} \mathrm{OH}\right): \lambda_{\max }=213,277 \mathrm{~nm}$. FT-IR $(\mathrm{KBr}): v=3433,1591,1490,1384,1332$, 1103, 824, $592 \mathrm{~cm}^{-1} .{ }^{1} \mathrm{H}-\mathrm{NMR}\left(300 \mathrm{MHz}, \mathrm{CD}_{3} \mathrm{OD}\right): \delta=7.67(\mathrm{~d}, J=7.5 \mathrm{~Hz}, 1 \mathrm{H}), 7.30-7.42(\mathrm{~m}, 5 \mathrm{H}), 6.46$ $(\mathrm{d}, J=7.5 \mathrm{~Hz}, 1 \mathrm{H}), 5.07\left(\mathrm{~s}, 2 \mathrm{H}, \mathrm{CH}_{2} \mathrm{Ph}\right), 3.96\left(\mathrm{t}, J=7.5 \mathrm{~Hz}, 2 \mathrm{H}, \mathrm{NH}_{2} \mathrm{CH}_{2} \mathrm{CH}_{2}\right), 2.84(\mathrm{t}, J=7.2 \mathrm{~Hz}, 2 \mathrm{H}$, $\left.\mathrm{NH}_{2} \mathrm{CH}_{2} \mathrm{CH}_{2}\right), 2.17$ (s, 3H, CH $)$ ppm. MS(APCI) $m / z(\%)=259(100)[\mathrm{M}+\mathrm{H}]^{+} . \mathrm{C}_{15} \mathrm{H}_{18} \mathrm{O}_{2} \mathrm{~N}_{2}(258.1)$ : calcd. C 69.77, H 6.98, N 10.85; found: C 70.23, H 7.17, N 10.49.

Synthesis of $N, N^{\prime}$-bis(4-(3-benzyloxy-2-methyl-4-pyridinone)ethyl)malonamide (3b). First $0.4 \mathrm{~g}$ ( $3^{\prime}$-aminoethyl)3-benzyloxy-2-methyl-4-pyridinone $(1.5 \mathrm{mmol})$ and $2 \mathrm{~mL}$ triethylamine were added in $50 \mathrm{~mL}$ dichloromethane, then mixture was stirred at $0{ }^{\circ} \mathrm{C}$ under $\mathrm{N}_{2}$. Then $75 \mu \mathrm{L}$ malonyl dichloride was diluted with $20 \mathrm{~mL}$ dichloromethane and then dropwise added slowly and consecutively keeping the temperature at $0{ }^{\circ} \mathrm{C}$ for $8 \mathrm{~h}$. The mixture was purified by chromatography on a silica-gel column with the methanol: chloroform $=1: 6$ as eluent, and the pure product was white powder $(0.26 \mathrm{~g}, 58 \%)$. UV-vis $\left(\mathrm{CH}_{3} \mathrm{OH}\right) \lambda_{\max }=213,279 \mathrm{~nm}$. FT-IR $(\mathrm{KBr}): v=2987,1961,1676,1623,1548,1507,1395,1252,1164$, $1034,880,835,752,703,613 \mathrm{~cm}^{-1} .{ }^{1} \mathrm{H}-\mathrm{NMR}\left(300 \mathrm{MHz}, \mathrm{CD}_{3} \mathrm{OD}\right): \delta=7.62(\mathrm{~d}, J=7.5 \mathrm{~Hz}, 2 \mathrm{H}), 7.28-7.44$ $(\mathrm{m}, 10 \mathrm{H}), 6.44(\mathrm{~d}, J=7.5 \mathrm{~Hz}, 2 \mathrm{H}), 5.04\left(\mathrm{~s}, 4 \mathrm{H}, \mathrm{CH}_{2} \mathrm{Ph}\right), 4.07\left(\mathrm{t}, J=6.0 \mathrm{~Hz}, 4 \mathrm{H}, \mathrm{NHCH}_{2} \mathrm{CH}_{2}\right), 3.45(\mathrm{t}$, $\left.J=6.0 \mathrm{~Hz}, 4 \mathrm{H}, \mathrm{NHCH}_{2} \mathrm{CH}_{2}\right), 3.08\left(\mathrm{~s}, 2 \mathrm{H}, \mathrm{COCH}_{2} \mathrm{CO}\right), 2.16\left(\mathrm{~s}, 6 \mathrm{H}, \mathrm{CH}_{3}\right) . \mathrm{MS}(\mathrm{APCI}) \mathrm{m} / z(\%)=585$ (100) $[\mathrm{M}+\mathrm{H}]^{+} . \mathrm{C}_{33} \mathrm{H}_{36} \mathrm{~N}_{6} \mathrm{O}_{4}$ (584): calcd. C 67.81, H 6.16, N 9.56; found: C 67.55, H 5.87, N 9.38.

Synthesis of $N_{,} N^{\prime}$-bis(4-(3-hydroxy-2-methyl-4-pyridinone)ethyl)malonamide (4b). First $40 \mathrm{mg} 10 \% \mathrm{Pd} / \mathrm{C}$ was added in a solution of $N, N^{\prime}$-bis(4-(3-benzyloxy-2-methyl-4-pyridinone)ethyl)malonamide $3 \mathbf{b}$ $(0.2 \mathrm{~g}, 3.7 \mathrm{mmol})$ in methanol $(50 \mathrm{~mL})$, then the mixture was stirred under $\mathrm{H}_{2}(1 \mathrm{~atm})$ for $4 \mathrm{~h}$ at room temperature. After filtration, the solvent was evaporated under reduced pressure and the product was obtained as the white powder $(0.12 \mathrm{~g}, 83 \%)$. UV-vis $\left(\mathrm{CH}_{3} \mathrm{OH}\right): \lambda_{\max }=279 \mathrm{~nm}$. FT-IR $(\mathrm{KBr}): v=3429$, $3069,2093,1654,1627,1561,1509,1353,1251,1035,831 \mathrm{~cm}^{-1} .{ }^{1} \mathrm{H}-\mathrm{NMR}\left(600 \mathrm{MHz}, \mathrm{CD}_{3} \mathrm{OD}\right): \delta=7.62$ $(\mathrm{d}, J=7.5 \mathrm{~Hz}, 2 \mathrm{H}), 6.46(\mathrm{~d}, J=7.5 \mathrm{~Hz}, 2 \mathrm{H}), 4.07\left(\mathrm{t}, J=6.0 \mathrm{~Hz}, 4 \mathrm{H}, \mathrm{NHCH}_{2} \mathrm{CH}_{2}\right), 3.45(\mathrm{t}, J=6.0 \mathrm{~Hz}, 4 \mathrm{H}$, $\left.\mathrm{NHCH}_{2} \mathrm{CH}_{2}\right), 3.08\left(2 \mathrm{H}, \mathrm{s}, \mathrm{COCH}_{2} \mathrm{CO}\right), 2.16\left(6 \mathrm{H}, \mathrm{s}, \mathrm{CH}_{3}\right) \mathrm{ppm}$. MS (APCI) $m / z(\%)=405(100)[\mathrm{M}+\mathrm{H}]^{+}$. $\mathrm{C}_{19} \mathrm{H}_{24} \mathrm{O}_{6} \mathrm{~N}_{4}$ (404): calcd. C 56.44, H 5.94, N 13.86; found: C 56.38, H 6.25, N 13.74.

Synthesis of N-(4-aminophenyl)-3-benzyloxy-2-methyl-4-pyridinone (2c). First 4.6 g 3-benzyoxy-2-methyl4-pyrone $(21.3 \mathrm{mmol})$ and $6.9 \mathrm{~g} p$-phenylenediamine $(63.9 \mathrm{mmol})$ were added in a mixture solvent of $40 \mathrm{~mL}$ EtOH and $20 \mathrm{~mL}$ water, then $0.5 \mathrm{~g} \mathrm{NaOH}$ was added and stirred at $90^{\circ} \mathrm{C}$ for $8 \mathrm{~h}$. After cooling, $2 \mathrm{M} \mathrm{HCl}$ was added until the $\mathrm{pH}=1$ and the solvent was evaporated. The residue was washed with acetone and dissolved in $20 \mathrm{~mL}$ water. The obtained solution was basified with $10 \mathrm{M} \mathrm{NaOH}$ until $\mathrm{pH}=12$ and extracted with dichloromethane $(5 \times 30 \mathrm{~mL})$. The organic phase was evaporated under 
reduced pressure and the residue was dissolved in $10 \mathrm{~mL}$ ethanol. Then $200 \mathrm{~mL}$ diethyl ether was added to afford the light yellow rude product, which was purified by chromatography on a silica gel column with a mixture of methanol: chloroform $=1: 20$ as eluent to afford a white powder $(6.25 \mathrm{~g}, 69 \%)$. UV-vis $\left(\mathrm{CH}_{3} \mathrm{OH}\right): \lambda_{\max }=207,250,279 \mathrm{~nm}$. FT-IR(KBr): $v=3434,3347(\mathrm{~N}-\mathrm{H}), 3232(\mathrm{C}-\mathrm{H}), 2961(\mathrm{C}-\mathrm{H})$, 1619 (C=O), 1567, 1511, 1479, 1358, 1281, 1162, 953, 843, 764, $703 \mathrm{~cm}^{-1} .{ }^{1} \mathrm{H}-\mathrm{NMR}\left(300 \mathrm{MHz}, \mathrm{CDCl}_{3}\right)$ : $\delta=7.44(\mathrm{~d}, J=6.8 \mathrm{~Hz}, 2 \mathrm{H}, 7.28-7.36(\mathrm{~m}, 3 \mathrm{H}), 7.23(\mathrm{~d}, J=6.8 \mathrm{~Hz}, 1 \mathrm{H}), 6.94(\mathrm{~d}, J=8.5 \mathrm{~Hz}, 2 \mathrm{H}), 6.66(\mathrm{~d}$, $J=8.5 \mathrm{~Hz}, 2 \mathrm{H}), 6.41(\mathrm{~d}, J=6.8 \mathrm{~Hz}, 1 \mathrm{H}), 5.24\left(\mathrm{~s}, 2 \mathrm{H}, \mathrm{CH}_{2} \mathrm{Ph}\right), 1.82\left(\mathrm{t}, J=7.5 \mathrm{~Hz}, 3 \mathrm{H}, \mathrm{CH}_{3}\right)$. MS (ESI) $\mathrm{m} / z$ $(\%)=307(100)[\mathrm{M}+\mathrm{H}]^{+}$. $\mathrm{C}_{19} \mathrm{H}_{18} \mathrm{O}_{2} \mathrm{~N}_{2}$ (306): calcd. C 74.51, $\mathrm{H}$ 5.88, N 9.15; found: $\mathrm{C} 74.32, \mathrm{H}$ 5.92, N 9.13.

Synthesis of $N, N^{\prime}$-bis(4-(3-benzyloxy-2-methyl-4-pyridinone)phenyl)malonamide (3c). First $1.6 \mathrm{~g} N$-(4-aminophenyl)3-benzyloxy-2-methyl-4-pyridinone $2 \mathrm{c}$ was stirred at $0{ }^{\circ} \mathrm{C}$ under $\mathrm{N}_{2}$. Then $300 \mu \mathrm{L}$ malonyl dichloride was diluted with $20 \mathrm{~mL}$ dichloromethane and then dropwise added slowly and consecutively keeping the temperature at $0{ }^{\circ} \mathrm{C}$ for $8 \mathrm{~h}$. The mixture was purified by chromatography on a silica-gel column with the methanol:chloroform $=1: 8$ as eluent, and the pure product was faint yellow powder $(1.5 \mathrm{~g}$, 86\%). UV-vis $\left(\mathrm{CH}_{3} \mathrm{OH}\right): \lambda_{\max }=208,251,281 \mathrm{~nm}$. FT-IR $(\mathrm{KBr}): v=3247,3189,3056,2926,1697,1625$, 1546, 1508, 1409, 1341, 1287, 1172, 1004, 988, 834, 751, $701 \mathrm{~cm}^{-1} .{ }^{1} \mathrm{H}-\mathrm{NMR}\left(300 \mathrm{MHz}, \mathrm{CD}_{3} \mathrm{OD}\right): \delta=7.64$ $(\mathrm{d}, J=8.5 \mathrm{~Hz}, 4 \mathrm{H}), 7.22-7.40(\mathrm{~m}, 2 \mathrm{H}), 7.03(\mathrm{~d}, J=8.5 \mathrm{~Hz}, 4 \mathrm{H}), 6.66(\mathrm{~d}, J=7.5 \mathrm{~Hz}, 4 \mathrm{H}), 6.42(\mathrm{~d}, J=7.5 \mathrm{~Hz}$, $2 \mathrm{H}), 5.08\left(\mathrm{~s}, 4 \mathrm{H}, \mathrm{CH}_{2} \mathrm{Ph}\right), 3.45\left(\mathrm{~s}, 2 \mathrm{H}, \mathrm{COCH}_{2} \mathrm{CO}\right), 1.71\left(\mathrm{t}, 6 \mathrm{H}, \mathrm{CH}_{3}\right) \mathrm{ppm}$. MS (ESI) $\mathrm{m} / z(\%)=681(100)$ $[\mathrm{M}+\mathrm{H}]^{+} . \mathrm{C}_{41} \mathrm{H}_{36} \mathrm{O}_{6} \mathrm{~N}_{4}$ (680): calcd. C 72.35, H 5.29, N 8.24; found: C 72.24, H 5.35, N 8.20.

Synthesis of N,N'-bis(4-(3-hydroxy-2-methyl-4-pyridinone)phenyl)malonamide (4c). First $50 \mathrm{mg} \mathrm{10 \%} \mathrm{Pd/C}$ was added in a solution of $N, N^{\prime}$-bis(4-(3-benzyloxy-2-methyl-4-pyridinone)phenyl)malonamide 3c $(0.23 \mathrm{~g}, 3.38 \mathrm{mmol})$ in methanol $(50 \mathrm{~mL})$, then the mixture was stirred under $\mathrm{H}_{2}(1 \mathrm{~atm})$ for $4 \mathrm{~h}$ at room temperature. After filtration, the solvent was evaporated under reduced pressure and the crude product was obtained as the white powder, which was recrystallized from methanol/diethyl ether $(0.15 \mathrm{~g}, 90 \%)$. UV-vis $\left(\mathrm{CH}_{3} \mathrm{OH}\right): \lambda_{\max }=209,251,292 \mathrm{~nm}$. FT-IR $(\mathrm{KBr}): v=3245(\mathrm{~N}-\mathrm{H}), 3121,3063,2928$ (C-H), 1693 (HNC=O), 1626(PyC=O), 1605, 1538, 1505, 1411, 1297, 1243, 1116, 1041, $834 \mathrm{~cm}^{-1}$. ${ }^{1} \mathrm{H}-\mathrm{NMR}$ $\left(600 \mathrm{MHz}, \mathrm{CD}_{3} \mathrm{OD}\right): \delta=7.87(\mathrm{~d}, J=7.8 \mathrm{~Hz}, 4 \mathrm{H}), 7.64(\mathrm{~d}, J=7.2 \mathrm{~Hz}, 2 \mathrm{H}), 7.38(\mathrm{~d}, J=8.5 \mathrm{~Hz}, 4 \mathrm{H}), 6.53$ (d, J = 7.2 Hz, 2H), 3.63 (s, 2H, COCH $\mathrm{CO}_{2} \mathrm{CO}, 2.15$ (s, 6H, CH 3 ) ppm. ${ }^{13} \mathrm{C}-\mathrm{NMR}\left(150 \mathrm{MHz}, \mathrm{CD}_{3} \mathrm{OD}\right)$ : $\delta=165.70,161.32,143.03,139.64,137.69,138.63,136.65,125.81,119.98,109.70,29.39,12.41$ ppm. MS (ESI) $m / z(\%)=523(100)[\mathrm{M}+\mathrm{Na}]^{+} . \mathrm{C}_{27} \mathrm{H}_{24} \mathrm{O}_{6} \mathrm{~N}_{4}$ (500): calcd. C 64.80; $\mathrm{H} 4.80, \mathrm{~N}$ 11.20; found: $\mathrm{C}$ 64.47, H 4.96, N 10.96 .

Synthesis of (3'-hydroxypropyl)-3-benzyloxy-2-methyl-4-pyridinone (2d). First 3 g 3-benzyoxy-2-methyl4-pyrone (13.9 mmol), $3.5 \mathrm{~mL} \mathrm{1,3-propanol} \mathrm{amine}(45.8 \mathrm{mmol})$ and $0.5 \mathrm{~g} \mathrm{NaOH}$ were added in a EtOH-water mixture $(20 / 15) \mathrm{mL}$, and then stirred at $70^{\circ} \mathrm{C}$ for $6 \mathrm{~h}$. After cooling, $2 \mathrm{M} \mathrm{HCl}$ was added until the $\mathrm{pH}=1$ and the reaction solution was evaporated under vacuum. The residue was washed with acetone and dissolved in $20 \mathrm{~mL}$ water. The obtained solution was basified with $10 \mathrm{M} \mathrm{NaOH}$ until $\mathrm{pH}=10$ and extracted with dichloromethane $(5 \times 30 \mathrm{~mL})$. The organic phase was evaporated and obtained the snow white powder $(2.9 \mathrm{~g}, 75 \%)$. UV-vis $\left(\mathrm{CH}_{3} \mathrm{OH}\right): \lambda_{\max }=216,274 \mathrm{~nm}$. FT-IR $(\mathrm{KBr})$ : $v=3336,1632,1522,1494,1419,1352,1263,1159,1157,1084,1035,960,842,754,706 \mathrm{~cm}^{-1} .{ }^{1} \mathrm{H}-\mathrm{NMR}$ $\left(300 \mathrm{MHz}, \mathrm{CD}_{3} \mathrm{OD}\right): \delta=7.62(\mathrm{~d}, J=7.4 \mathrm{~Hz}, 1 \mathrm{H}), 7.32-7.46(5 \mathrm{H}, \mathrm{m}), 6.46(\mathrm{~d}, J=7.4 \mathrm{~Hz}, 1 \mathrm{H}), 5.06(\mathrm{~s}$, $\left.2 \mathrm{H}, \mathrm{CH}_{2} \mathrm{Ph}\right), 4.13\left(\mathrm{t}, J=7.1 \mathrm{~Hz}, 2 \mathrm{H}, \mathrm{HOCH}_{2} \mathrm{CH}_{2}\right), 4.03\left(\mathrm{t}, J=7.1 \mathrm{~Hz}, 2 \mathrm{H}, \mathrm{HOCH}_{2} \mathrm{CH}_{2} \mathrm{CH}_{2}\right), 2.13(\mathrm{~s}$, $\left.3 \mathrm{H}, \mathrm{CH}_{3}\right), 2.00\left(\mathrm{t}, J=6.2 \mathrm{~Hz}, 2 \mathrm{H}, \mathrm{HOCH}_{2} \mathrm{CH}_{2} \mathrm{CH}_{2}\right) \mathrm{ppm}$. MS (APCI) $m / z(\%)=274(100)[\mathrm{M}+\mathrm{H}]^{+}$. $\mathrm{C}_{16} \mathrm{H}_{19} \mathrm{O}_{3} \mathrm{~N}$ (273): calcd. C 70.33,H 6.96, N 5.13; found: C 70.08, H 6.78, N 5.26.

Synthesis of $N, N^{\prime}$-bis(4-(3-benzyloxy-2-methyl-4-pyridinone)hydroxypropyl)malonicester (3d). First $0.5 \mathrm{~g}$ (3'-hydroxypropyl)-3-benzyloxy-2-methyl-4-pyridinone $(1.83 \mathrm{mmol})$ and $2 \mathrm{~mL}$ triethylamine were added in $50 \mathrm{~mL}$ dichloromethane, then mixture was stirred at $0{ }^{\circ} \mathrm{C}$ under $\mathrm{N}_{2}$. Then $100 \mu \mathrm{L}$ malonyl dichloride was diluted with $20 \mathrm{~mL}$ dichloromethane and then dropwise added slowly and consecutively keeping the temperature at $0{ }^{\circ} \mathrm{C}$ for $6 \mathrm{~h}$. The mixture was purified by chromatography 
on a silica-gel column with the methanol:chloroform $=1: 8$ as eluent, and the pure product was faint yellow oil $(0.2 \mathrm{~g}, 37 \%)$. UV-vis $\left(\mathrm{CH}_{3} \mathrm{OH}\right): \lambda_{\max }=218,274 \mathrm{~nm}$. FT-IR (KBr): $v=2925,1742,1647,1494$, 1384, 1263, 1159, 1083, 1035, 842, 753, $706 \mathrm{~cm}^{-1} .{ }^{1} \mathrm{H}-\mathrm{NMR}\left(300 \mathrm{MHz}, \mathrm{CD}_{3} \mathrm{OD}\right): \delta=7.18-7.36(\mathrm{~m}, 12 \mathrm{H})$, $6.35(\mathrm{~d}, \mathrm{~J}=7.4 \mathrm{~Hz}, 2 \mathrm{H}), 5.08\left(\mathrm{~s}, 4 \mathrm{H}, \mathrm{CH}_{2} \mathrm{Ph}\right), 4.06\left(\mathrm{~d}, \mathrm{~J}=4.5 \mathrm{~Hz}, 4 \mathrm{H}, \mathrm{OCH}_{2} \mathrm{CH}_{2} \mathrm{CH}_{2}\right), 3.83(\mathrm{t}, J=6.6 \mathrm{~Hz}$, $\left.2 \mathrm{H}, \mathrm{OCH}_{2} \mathrm{CH}_{2} \mathrm{CH}_{2}\right), 3.36$ (s, 2H, $\left.\mathrm{COCH}_{2} \mathrm{CO}\right), 2.02\left(\mathrm{~s}, 6 \mathrm{H}, \mathrm{CH}_{3}\right), 1.85-1.95\left(\mathrm{~m}, 4 \mathrm{H}, \mathrm{OCH}_{2} \mathrm{CH}_{2} \mathrm{CH}_{2}\right) \mathrm{ppm}$. MS (APCI) $m / z(\%)=308(100)[\mathrm{M}+2 \mathrm{H}]^{+}$. $\mathrm{C}_{35} \mathrm{H}_{38} \mathrm{O}_{8} \mathrm{~N}_{2}$ (614): calcd. C 68.40, H 6.19, N 4.55; found: C 68.28, H 6.42, N 4.37 .

Synthesis of $N, N^{\prime}$-Bis(4-(3-hydroxy-2-methyl-4-pyridinone)-hydroxyethyl)-malonic ester (4d). First $40 \mathrm{mg} 10 \%$ $\mathrm{Pd} / \mathrm{C}$ was added in a solution of $N, N^{\prime}$-bis(4-(3-hydroxy-2-methyl-4-pyridinone)hydroxyethyl)-malonic ester $(0.22 \mathrm{~g}, 0.34 \mathrm{mmol})$ in methanol $(50 \mathrm{~mL})$, then the mixture was stirred under $\mathrm{H}_{2}(1 \mathrm{~atm})$ for $6 \mathrm{~h}$ at room temperature. After filtration, the solvent was evaporated under reduced pressure and the crude product was obtained as the white powder $(0.11 \mathrm{~g}, 71 \%)$. UV-vis $\left(\mathrm{CH}_{3} \mathrm{OH}\right): \lambda_{\max }=284 \mathrm{~nm}$. FT-IR $(\mathrm{KBr}) \mathrm{v} / \mathrm{cm}^{-1}$ : 3399, 2965, 2426, 1731, 1632, 1508, 1383, 1255, 1162, 1032, 827. ${ }^{1} \mathrm{H}-\mathrm{NMR}(600 \mathrm{MHz}$, $\left.\mathrm{CD}_{3} \mathrm{OD}\right): \delta=7.99(\mathrm{~d}, J=7.2 \mathrm{~Hz}, 2 \mathrm{H}), 6.88(\mathrm{~d}, J=7.2 \mathrm{~Hz}, 2 \mathrm{H}), 4.39\left(\mathrm{t}, J=4.5 \mathrm{~Hz}, 4 \mathrm{H}, \mathrm{OCH}_{2} \mathrm{CH}_{2} \mathrm{CH}_{2}\right)$, $4.22\left(\mathrm{t}, \mathrm{J}=6.6 \mathrm{~Hz}, 4 \mathrm{H}, \mathrm{OCH}_{2} \mathrm{CH}_{2} \mathrm{CH}_{2}\right), 3.67\left(\mathrm{~s}, 2 \mathrm{H}, \mathrm{COCH}_{2} \mathrm{CO}\right), 2.17\left(\mathrm{~s}, 6 \mathrm{H}, \mathrm{CH}_{3}\right), 2.00-2.20(\mathrm{~m}, 4 \mathrm{H}$, $\left.\mathrm{OCH}_{2} \mathrm{CH}_{2} \mathrm{CH}_{2}\right) ; \mathrm{MS}$ (APCI) $m / z(\%)=435(100)[\mathrm{M}+\mathrm{H}]^{+} . \mathrm{C}_{21} \mathrm{H}_{26} \mathrm{O}_{8} \mathrm{~N}_{2}$ (434): calcd. C 58.06, $\mathrm{H}$ 5.99, N 6.45; found: C 58.13, H 6.07, N 6.21.

Synthesis of (3'-Hydroxyethyl)-3-benzyloxy-2-methyl-4-pyridinone (2e). First $4.3 \mathrm{~g}$ 3-benzyoxy-2-methyl4-pyrone (19.9 mmol), $3.3 \mathrm{~mL} \mathrm{2-aminoethanol}(49.3 \mathrm{mmol})$ and $0.5 \mathrm{~g} \mathrm{NaOH}$ were added in a mixture solvent of $20 \mathrm{~mL}$ EtOH and $15 \mathrm{~mL}$ water mixture, and then stirred at $70^{\circ} \mathrm{C}$ for $6 \mathrm{~h}$. After cooling, $2 \mathrm{M}$ $\mathrm{HCl}$ was added until the $\mathrm{pH}=1$ and the reaction solution was evaporated under vacuum. The residue was washed with acetone and dissolved in $20 \mathrm{~mL}$ water. The obtained solution was basified with $10 \mathrm{M} \mathrm{NaOH}$ until $\mathrm{pH}=10$ and extracted with dichloromethane $(5 \times 30 \mathrm{~mL})$. The organic phase was evaporated and obtained the snow white powder $(4.6 \mathrm{~g}, 89 \%)$. UV-vis $\left(\mathrm{CH}_{3} \mathrm{OH}\right): \lambda_{\max }=215,270 \mathrm{~nm}$. FT-IR (KBr): $v=3335,1636(\mathrm{C}=\mathrm{O}), 1523,1492,1342,1295,1271,1157,1079,1075,1032,969,831$, 768, $708 \mathrm{~cm}^{-1} .{ }^{1} \mathrm{H}-\mathrm{NMR}\left(300 \mathrm{MHz}, \mathrm{CD}_{3} \mathrm{OD}\right): \delta=8.32(1 \mathrm{H}, \mathrm{d}, J=7.2 \mathrm{~Hz}), 7.36-7.44(\mathrm{~m}, 5 \mathrm{H}), 7.23$ $(\mathrm{d}, J=7.2 \mathrm{~Hz}, 1 \mathrm{H}), 5.17\left(\mathrm{~s}, 2 \mathrm{H}, \mathrm{CH}_{2} \mathrm{Ph}\right), 4.47\left(\mathrm{t}, J=7.5 \mathrm{~Hz}, 2 \mathrm{H}, \mathrm{HOCH}_{2} \mathrm{CH}_{2}\right), 3.89(\mathrm{t}, J=7.5 \mathrm{~Hz}, 2 \mathrm{H}$, $\mathrm{HOCH}_{2} \mathrm{CH}_{2}$ ), 2.51 (s, 3H, $\mathrm{CH}_{3}$ ) ppm. MS (APCI) $m / z(\%)=260(100)[\mathrm{M}+\mathrm{H}]^{+} . \mathrm{C}_{15} \mathrm{H}_{17} \mathrm{O}_{3} \mathrm{~N}(259)$ : calcd. C 69.50, H 6.56, N 5.41; found: C 69.84, H 6.72, N 5.38.

Synthesis of $N, N^{\prime}$-bis(4-(3-benzyloxy-2-methyl-4-pyridinone)-Hydroxyethyl)-malonic ester (3e). First $0.5 \mathrm{~g}$ (3'-hydroxyethyl)-3-benzyloxy-2-methyl-4-pyridinone $(1.9 \mathrm{mmol})$ and $2 \mathrm{~mL}$ triethylamine were added in $50 \mathrm{~mL}$ dichloromethane, then mixture was stirred at $0{ }^{\circ} \mathrm{C}$ under $\mathrm{N}_{2}$. Then $100 \mu \mathrm{L}$ malonyl dichloride was diluted with $20 \mathrm{~mL}$ dichloromethane and then dropwise added slowly and consecutively keeping the temperature at $0{ }^{\circ} \mathrm{C}$ for $6 \mathrm{~h}$. The mixture was purified by chromatography on a silica-gel column with the methanol: chloroform $=1: 8$ as eluent, and the pure product was faint yellow oil $(0.12 \mathrm{~g}, 35 \%)$. $\mathrm{UV} / \mathrm{vis}\left(\mathrm{CH}_{3} \mathrm{OH}\right): \lambda_{\max }=220,273 \mathrm{~nm}$. FT-IR $(\mathrm{KBr}): v=2921,2851,1748,1625,1561,1512,1251,1230$, 1108, 1064, 825, 737, $701 \mathrm{~cm}^{-1} .{ }^{1} \mathrm{H}-\mathrm{NMR}\left(400 \mathrm{MHz}, \mathrm{CD}_{3} \mathrm{OD}\right): \delta=8.32(\mathrm{~d}, J=7.2 \mathrm{~Hz}, 2 \mathrm{H}), 7.36-7.44(\mathrm{~m}$, $10 \mathrm{H}), 7.26(\mathrm{~d}, \mathrm{~J}=7.2 \mathrm{~Hz}, 2 \mathrm{H}), 5.17\left(\mathrm{~s}, 4 \mathrm{H}, \mathrm{CH}_{2} \mathrm{Ph}\right), 4.47\left(\mathrm{t}, J=7.8 \mathrm{~Hz}, 2 \mathrm{H}, \mathrm{OCH}_{2} \mathrm{CH}_{2}\right), 3.89(\mathrm{t}, J=7.8 \mathrm{~Hz}$, $\left.2 \mathrm{H}, \mathrm{OCH}_{2} \mathrm{CH}_{2}\right), 3.69$ (s, 2H, $\left.\mathrm{COCH}_{2} \mathrm{CO}\right), 2.51\left(\mathrm{~s}, 3 \mathrm{H}, \mathrm{CH}_{3}\right) . \mathrm{MS}(\mathrm{APCI}) m / z(\%)=587(100)[\mathrm{M}+\mathrm{H}]^{+}$. $\mathrm{C}_{33} \mathrm{H}_{34} \mathrm{O}_{8} \mathrm{~N}_{2}$ (586): calcd. C 67.58,; $\mathrm{H} 5.80, \mathrm{~N} 4.78$; found: C 67.66, H 6.01, N 4.64.

Synthesis of $N, N^{\prime}$-Bis(4-(3-hydroxy-2-methyl-4-pyridinone)-hydroxyethyl)-malonic ester (4e). First $40 \mathrm{mg}$ $10 \% \mathrm{Pd} / \mathrm{C}$ was added in a solution of $N, N^{\prime}$-bis(4-(3-hydroxy-2-methyl-4-pyridinone)-hydroxyethyl)malonic ester $(0.19 \mathrm{~g}, 0.34 \mathrm{mmol})$ in methanol $(50 \mathrm{~mL})$, then the mixture was stirred under $\mathrm{H}_{2}(1 \mathrm{~atm})$ for $6 \mathrm{~h}$ at room temperature. After filtration, the solvent was evaporated under reduced pressure and the crude product was obtained as the white powder, which was recrystallized from methanol/diethyl ether $(0.10 \mathrm{~g}, 76 \%)$. UV-vis $\left(\mathrm{CH}_{3} \mathrm{OH}\right) \lambda_{\max }=281 \mathrm{~nm}$. FT-IR $(\mathrm{KBr}): v=3367,2963,1736,1628,1567$, $1508,1460,1384,1352,1251,1150,1110,1026,831,599 \mathrm{~cm}^{-1} .{ }^{1} \mathrm{H}-\mathrm{NMR}\left(600 \mathrm{MHz}, \mathrm{CD}_{3} \mathrm{OD}\right): \delta=8.31$ $(\mathrm{d}, J=7.2 \mathrm{~Hz}, 2 \mathrm{H}), 7.25(\mathrm{~d}, J=7.2 \mathrm{~Hz}, 2 \mathrm{H}), 4.38\left(\mathrm{t}, J=7.8 \mathrm{~Hz}, 2 \mathrm{H}, \mathrm{OCH}_{2} \mathrm{CH}_{2}\right), 3.91(\mathrm{t}, J=7.8 \mathrm{~Hz}, 2 \mathrm{H}$, 
$\mathrm{OCH}_{2} \mathrm{CH}_{2}$ ), 3.67 (s, 2H, $\left.\mathrm{COCH}_{2} \mathrm{CO}\right), 2.49$ (s, 3H, $\mathrm{CH}_{3}$ ). MS (APCI) $m / z(\%)=407(100)[\mathrm{M}+\mathrm{H}]^{+}$. $\mathrm{C}_{19} \mathrm{H}_{22} \mathrm{O}_{8} \mathrm{~N}_{2}$ (406): calcd. C 56.16, H 5.42, N 6.90; found: C 56.32, H 5.63, N 7.02.

\subsection{Metal Complexation Solutions}

In all the complexation studies in aqueous solution, the water was distilled three times and the atmospheric $\mathrm{CO}_{2}$ was excluded from the system with a purging steam of $\mathrm{N}_{2}$ under $80{ }^{\circ} \mathrm{C}$. The $\mathrm{UO}_{2}\left(\mathrm{NO}_{3}\right)_{2} \cdot 6 \mathrm{H}_{2} \mathrm{O}$ is analytical grade, the buffered solution were $\mathrm{NaAc} / \mathrm{HAc}(\mathrm{pH}=5.5)$ and Tris- $\mathrm{HCl}(\mathrm{pH}=7.4,9.0)$. All the ligands were synthesized and dissolved into the water, except the solvent of the ligand 4c was DMSO: $\mathrm{H}_{2} \mathrm{O}=1: 9$ to ensure all the ligands was dissolved. The ligands concentration $\left(\mathrm{C}_{\mathrm{L}}\right)$ was $2.0 \times 10^{-3} \mathrm{~mol} / \mathrm{L}$ and the $\mathrm{UO}_{2}{ }^{2+}\left(\mathrm{C}_{\mathrm{M}}\right)$ concentration was $2.0 \times 10^{-3} \mathrm{~mol} / \mathrm{L}$, then added the solutions into the $10 \mathrm{~mL}$ comparison tubes by different volume, the total concentration $\left(C_{L}+C_{M}\right)$ was $2.0 \times 10^{-3} \mathrm{~mol} / \mathrm{L}$ for all complexation samples.

\section{Conclusions}

In summary, five new ligands of bis(3-hydroxy-4-pyridinone) tetradentate ligands were synthesized and characterized. The stability constants determined in this study provide evidence for the extremely high affinities of the ligands for $\mathrm{UO}_{2}{ }^{2+}$ complexes. The evident difference in $\log \mathrm{K}_{\mathrm{cond}}$ compared with the similar structural ligands, emphasized the superior affinity for $\mathrm{UO}_{2}{ }^{2+}$ of the $4 \mathbf{b}$ ligand. At $\mathrm{pH} 7.4$, the $4 \mathrm{~b}$ ligand shows a high constant of 22.7 , confirming this compound as an effective chelator for $\mathrm{UO}_{2}{ }^{2+}$.

Acknowledgments: The authors are thankful for financial support from the National Natural Science Foundation of China (Project No. 21301142), Applied Basic Research Program of Sichuan Province (2014JY0170), Open Project of State Key Laboratory Cultivation Base for Nonmetal Composites and Functional (project no. 14zdfk05), Major Project of the Education Department of Sichuan Province (project no. 13ZA0172), Southwest University of Science and Technology Outstanding Youth Foundation (project no. 13zx9107).

Author Contributions: Bo Jin and Rufang Peng conceived and designed the experiments; Rongzong Zheng performed the experiments; Shijin Chu analyzed the data; Rongzong Zheng and Bo Jin wrote the paper.

Conflicts of Interest: The authors declare no conflict of interest.

\section{References}

1. Hamilton, J.G. The metabolic properties of the fission products and actinide elements. Rev. Mod. Phys. 1948, 20, 718-728. [CrossRef]

2. Brugge, D.J.; Lemos, L.D.; Oldmixon, B. Exposure pathways and health effects associated with chemical and radiological toxicity of natural uranium: A review. Rev. Environ. Health 2005, 20, 177-193. [CrossRef] [PubMed]

3. Morss, L.R.; Edelstein, N.M.; Fuger, J.; Katz, J.J. The Chemistry of the Actinide and Transactinide Elements; Springer: Dordrecht, The Netherlands, 2006; pp. 3339-3440.

4. Guzmán, L.; Durán-Lara, E.F.; Donoso, W.; Nachtigall, F.M.; Santos, L.S. In Vivo Nanodetoxication for acute uranium exposure. Molecules 2015, 20, 11017-11033. [CrossRef] [PubMed]

5. Liu, G.; Bruenger, F.W.; Miller, S.C.; Afri, A.M. Molecular structure and biological and pharmacological properties of 3-hydroxy-2-methyl-1-( $\beta$-D-ribofuranosyl or pyranosyl)-4-pyridinone: Potential iron overload drugs for oral administration. Bio. Med. Chem. Lett. 1998, 8, 3007-3080. [CrossRef]

6. Santos, M.A.; Gil, M.; Marques, S.; Gano, L.; Cantinho, G.J. N-Carboxyalkyl derivatives of 3-hydroxy-4-pyridinones: Synthesis, complexation with $\mathrm{Fe}(\mathrm{III}), \mathrm{Al}(\mathrm{III})$ and $\mathrm{Ga}(\mathrm{III})$ and in vivo evaluation. J. Inorg. Biochem. 2002, 92, 43-54. [CrossRef]

7. Santos, M.A.; Gama, S.; Gano, L.; Farkas, E. Bis(3-hydroxy-4-pyridinone)-EDTA derivative as a potential therapeutic Al-chelating agent. Synthesis, solution studies and biological assays. J. Inorg. Biochem. 2005, 99, 1845-1852. [CrossRef] [PubMed]

8. Santos, M.A.; Grazina, R.; Buglyo, P.; Gama, S.; Farkas, E. A new bipodal carboxy-bis (hydroxypyridinonate) ligand. Synthesis and complexation with copper(II), nicker(II) and zinc(II) in aqueous solution. Polyhedron 2002, 21, 2609-2616. 
9. Leite, A.; Silva, A.M.G.; Nunes, A.; Andrade, M.; Sousa, C.; Silva, L.C.; Gameiro, P.; Castro, B.D.; Rangel, M. Novel tetradentate chelators derived from 3-hydroxy-4-pyridinone units: synthesis, characterization and aqueous solution properties. Tetrahedron 2011, 67, 4009-4016. [CrossRef]

10. Zhou, T.; Liu, Z.D.; Neubert, H.; Kong, X.L.; Ma, Y.M.; Hider, R.C. High affinity iron(III) scavenging by a novel hexadentate 3-hydroxypyridin-4-one-based dendrimer: Synthesis and characterization. Bioorg. Med. Chem. Lett. 2005, 15, 5007-5011. [CrossRef] [PubMed]

11. Grazina, R.; Gano, L.; Šebestík, J.; Santos, M.A. New tripodal hydroxypyridinone based chelating agents for $\mathrm{Fe}(\mathrm{III}), \mathrm{Al}(\mathrm{III})$ and $\mathrm{Ga}(\mathrm{III})$ : Synthesis, physico-chemical properties and bioevaluation. J. Inorg. Biochem. 2009, 103, 262-273. [CrossRef] [PubMed]

12. Salaheldin, A.M.; Al-Sheikh, M.A. $\beta$-Enamino esters in heterocyclic synthesis: Synthesis of pyrazolone and pyridinone derivatives. Molecules 2010, 15, 4359-4368. [CrossRef] [PubMed]

13. Xu, B.; Kong, X.L.; Zhou, T.; Qiu, D.H.; Chen, Y.L.; Li, M.S. Synthesis, iron(III)-binding affinity and in vitro evaluation of 3-hydroxypyridin-4-one hexadentate ligands as potential antimicrobial agents. Bioorg. Med. Chem. Lett. 2011, 21, 6376-6380. [CrossRef] [PubMed]

14. Santos, M.A.; Marques, S.M.; Chaves, S. Hydroxypyridinones as privileged chelating structures for the design of medicinal drugs. Coord. Chem. Rev. 2012, 256, 240-259. [CrossRef]

15. Crisponi, G.; Remeli, M. Iron chleating agent for the treatment of iron overload. Coord. Chem. Rev. 2008, 252, 1225-1240. [CrossRef]

16. Santos, M.A. Recent development on 3-hydroxy-4-pyridinones with respect to their clinical applications Mono and combined ligand approaches. Coord. Chem. Rev. 2008, 252, 1213-1224. [CrossRef]

17. Gama, S.; Gil, M.; Gano, L.; Farkas, E.; Santos, M.A. Combined chelation of bi-functional bis-hydroxypiridinone and mono-hydroxypiridinone: Synthesis, solution and in vivo evaluation. J. Inorg. Biochem. 2009, 103, 288-298. [CrossRef] [PubMed]

18. Santos, M.A.; Gama, S.; Gano, L.; Cantinho, G.; Frakas, E. A new bis(3-hydroxy-4-pyridinone)-IDA derrivatives as a potential therapeutic chelating agent. Synthesis,metal-complexation and biological assays. Dalton Trans. 2004, 21, 3772-3781. [CrossRef] [PubMed]

19. Zhou, T.; Neubert, H.; Liu, D.Y.; Liu, Z.D.; Ma, Y.M.; Kong, X.L.; Luo, W. Iron dendrimers: A novel approach for the treatment of Haemochromatosis. J. Med. Chem. 2006, 49, 4171-4182. [CrossRef] [PubMed]

20. Leydier, A.; Lecerclé, D.; Rostaing, S.P.; Reguillon, A.F.; Taran, F.; Lemaire, M. Sequestering agent for uranyl chelation: New binaphtyl ligands. Tetrahedron Lett. 2011, 52, 3973-3977. [CrossRef]

21. Hider, R.C.; Roy, S.; Ma, Y.M.; Kong, X.L.; Preston, J. The potential application of iron chelators for the treatment of neurodegenerative disease. Metallomics 2011, 3, 239-249. [CrossRef] [PubMed]

22. Santos, M.A.; Grazina, R.; Neto, A.Q.; Cantinho, G.; Gano, L.; Patrício, L. Synthesis, chelating poperties towards gallium and biological evaluation of two $\mathrm{N}$-substituted 3-hydroxy-4-pyridinones. J. Inorg. Biochem. 2000, 78, 303-311. [CrossRef]

23. Leydier, A.; Lecerclé, D.; Rostaing, S.P.; Réguillona, A.F.; Taran, F.; Lemairea, M. Sequestering agents for uranyl chelation: New calixarene ligands. Tetrahedron 2008, 64, 11319-11324. [CrossRef]

24. Hoehne, M.S.; Deblonde, G.J.P.; Abergel, R.J. Solution thermodynamic evaluation of hydroxypyridinonate chelators 3,4,3-LI(1,2-HOPO) and 5-LIO(Me-3,2-HOPO) for $\mathrm{UO}_{2}(\mathrm{VI})$ and $\mathrm{Th}(\mathrm{IV})$ decorporation. Radiochim. Acta 2013, 101, 359-366. [CrossRef]

25. Szigethy, G.; Raymond, K.N. Hexadentate Terephthalamide (bis-hydroxypyridinone) ligands for uranyl chelation: Structural and thermodynamic consequences of ligand variation. J. Am. Chem. Soc. 2011, 133, 7942-7956. [CrossRef] [PubMed]

26. Chaves, S.; Capelo, A.; Areias, L.; Marpues, S.M.; Gano, L.; Esteves, M.A.; Santos, M.A. A novel tripodal tris-hydroxypyrimidinone sequestering agent for trivalent hard metal ions: Synthesis, complexation and in vivo studies. Dalton Trans. 2013, 42, 6033-6045. [CrossRef] [PubMed]

27. Bartholomä, M.D. Recent developments in the design of bifunctional chelators for metal-based radiopharmaceuticals used in positron emission tomography. Inorg. Chim. Acta 2012, 389, 36-51. [CrossRef]

28. Chaves, S.; Marques, S.M.; André, M.F. New tris(hydroxypyridinones) as iron and aluminium sequestering agents: Synthesis, complexation and in vivo studies. Chem. Eur. J. 2010, 16, 10535-10545. [CrossRef] [PubMed] 
29. Xu, J.D.; Raymond, K.N. Uranyl sequestering agents: Correlation of properties and efficacy with structure for $\mathrm{UO}_{2}{ }^{2+}$ complexes of linear tetradentate 1-methyl-3-hydroxy-2(1H)-pyridinone ligands. Inorg. Chem. 1999, 38, 308-315. [CrossRef]

30. Domingo, J.L.; Ortega, A.; Llobet, J.M.; Paternain, J.L.; Corbella, J. The effects of uranium on reproduction, gestation, and postnatal survival in mice. Res. Commun. Pathol. Pharmacol. 1989, 64, 161-164.

31. Stradling, G.N.; Gray, S.A.; Moody, J.C.; Ellender, M. Efficacy of Tiron for Enhancing the Excretion of Uranium from the Rat. Hum. Exp. Toxicol. 1991, 10, 195-198. [CrossRef] [PubMed]

Sample Availability: not availiable.

(C) 2016 by the authors; licensee MDPI, Basel, Switzerland. This article is an open access article distributed under the terms and conditions of the Creative Commons by Attribution (CC-BY) license (http:/ / creativecommons.org/licenses/by/4.0/). 